\title{
A frameshift mutation in the gene for PAX3 in a girl with spina bifida and mild signs of Waardenburg syndrome
}

Frans A Hol, Ben C J Hamel, Monique P A Geurds, Reinier A Mullaart, Frederic G Barr, Roberto A Macina, Edwin C M Mariman

\begin{abstract}
Neural tube defects (NTD) are among the most prevalent congenital malformations in man. Based on the molecular defect of Splotch, an established mouse model for NTD, and on the clinical association between NTD and Waardenburg syndrome (WS), mutations in the PAX3 gene can be expected to act as factors predisposing to human NTD. To test this hypothesis, 39 patients with familial NTD were screened by SSC analysis for mutations in exons 2 to 6 of the human PAX3 gene. One patient with lumbosacral meningomyelocele was identified with a 5 bp deletion in exon 5 approximately 55 bp upstream of the conserved homeodomain. The deletion causes a frameshift with a stop codon almost immediately after the mutated site. Clinical investigation of the index patient indicated mild signs of WS type I. Varying signs of this syndrome were found to cosegregate with the mutation in the family. Our results support the hypothesis that mutations in the gene for PAX3 can predispose to NTD, but also show that, in general, mutations within or near the conserved domains of the PAX3 protein are only very infrequently involved in familial NTD.
\end{abstract}

( $($ Med Genet 1995;32:52-56)

Neural tube defects (NTD) are congenital malformations resulting from incomplete closure of the neural tube during early embryonic development. In man, their prevalence at birth is about $1 / 1000$. NTD are thought to result from an interaction between environmental and predisposing genetic factors which interfere with the normal neurulation process. ${ }^{1}$ The involvement of genetic factors is reflected by the increased recurrence risk for close relatives of patients. Only about 3\% of all cases are familial and large families with multiple cases are extremely rare. ${ }^{23}$ Therefore, it is practically impossible to identify the underlying genetic factors by linkage studies. ${ }^{4}$ Elucidation of these factors is essential to understanding the pathogenesis of NTD and for the identification of persons at risk of having affected offspring.

An alternative approach to shed more light on these genetic factors is the analysis of suitable animal models. In one of the models for NTD, Splotch, ${ }^{15}$ mutations in the gene for Pax $^{6}{ }^{6}$ which is expressed in defined regions of the developing neural tube and in various neural crest derived tissues, ${ }^{7}$ can cause NTD in homozygous embryos. ${ }^{8}$ In the heterozygous state, Pax3 mutations do not cause but seem to predispose to NTD in a strain specific manner. ${ }^{910}$ A similar situation may exist in humans, where mutations in the PAX3 gene are known to cause Waardenburg syndrome (WS), ${ }^{11-17}$ a condition which is occasionally associated with NTD. ${ }^{18-24}$ Therefore, it is tempting to speculate that in man, too, mutations in the gene for PAX3 (also referred to as $\mathrm{HuP} 2$ ) constitute genetic risk factors for NTD. If so, their frequency should be increased in patients with this disorder.

\section{Materials and methods}

ASCERTAINMENT OF PATIENTS AND DNA ISOLATION

Patients were selected from the Dutch population in collaboration with the patient organisation BOSK and from the records of the Nijmegen hospital departments. Thirty nine families were selected with more than one patient who had an affected third degree or closer relative (first cousin, great aunt, or great uncle of the proband). ${ }^{3}$ Genomic DNA was isolated from one patient from every family according to the procedure of Miller et al. ${ }^{25}$ The types of NTD in the test patients were spina bifida (37), encephalocele (1), and craniorachischisis (1).

\section{SSC ANALYSIS}

DNA fragments overlapping exons 2 to 6 of the human PAX3 gene were amplified by the polymerase chain reaction (PCR) from genomic DNA together with $5^{\prime}$ and $3^{\prime}$ flanking intron sequences. Amplification was carried out in a total volume of $25 \mu$ l containing $50 \mathrm{ng}$ of genomic DNA, $0.45 \mathrm{mmol} / 1$ of each primer, $0.1 \mathrm{mmol} / 1 \mathrm{dCTP}, 0.4 \mathrm{mmol} / 1 \mathrm{dATP}, 0.4 \mathrm{mmol} /$ $1 \mathrm{dGTP}, 0.4 \mathrm{mmol} / 1 \mathrm{dTTP}, 0 \cdot 1 \mu \mathrm{l}\left[\alpha^{32} \mathrm{P}\right] \mathrm{dCTP}$ (Amersham) in PCR buffer $(50 \mathrm{mmol} / 1 \mathrm{KCl}$, $10 \mathrm{mmol} / 1$ Tris- $\mathrm{HCl}, \mathrm{pH} 8.3,1 \mathrm{mmol} / 1 \mathrm{DTE}$, $0.001 \%$ gelatine, $1.5-6 \mathrm{mmol} / 1 \mathrm{MgCl}_{2}$ ) with $0.5 \mathrm{U}$ Taq DNA polymerase (Boehringer Mannheim). Samples were denatured at $92^{\circ} \mathrm{C}$ for five minutes and then subjected to 35 cycles of amplification: $92^{\circ} \mathrm{C}$ for 50 seconds, $55^{\circ} \mathrm{C}$ for 50 seconds, $72^{\circ} \mathrm{C}$ for one minute $30 \mathrm{sec}$ onds. Exon 2 was analysed as two partly overlapping fragments. The following primers were used for amplification (fig 1), some of which are identical to those reported by Tassabehji $e t$ 


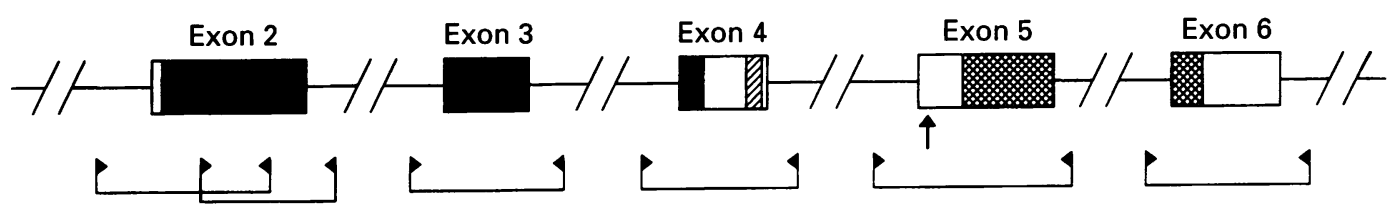

Figure 1 Schematic respresentation of the part of the PAX-3 gene that was subjected to mutation screening. The position of the conserved domains is indicated by filled boxes (paired domain), a single hatched box (octapeptide), and double hatched boxes (homeodomain). Arrowheads with connecting bars represent the amplification primers and amplified hatched boxes (homeodomain). Arrowheads with connectir
fragments. The vertical arrow marks the site of deletion.

$a l^{11}$ : exon 2, $5^{\prime}$ fragment (266 bp): 5'-GAAGACTGCGAAATTACGTGCTGC-3' and 5'-ACAGGATCTTGGAGACGCAGCC-3'; exon 2, 3' fragment (208 bp): 5'-AACCACATCCGCCACAAGATCG-3' and $5^{\prime}-$ GACCACAGTCTGGGAGCCAGGAGG-3'; exon 3 (237 bp): 5'-CACCTGGCCCAGGGTACCGGGTAC-3' and 5'-CGGGGTAATAGCGACTGACTGTC-3'; exon 4 (242 bp): 5'-AGCCCTGCTTGTCTCAACCATGTG-3' and 5'-TGCCCTCCAAGTCACCCAGCAAGT-3'; exon 5 (304 bp): 5'GACTTGGATCAATCTCAGTTTT $-3^{\prime}$ and 5'-TAGGACACGGAGGTTTGG-3'; exon 6 (250 bp) 5'-TTCATCAGTGAAATCCTTAAATT- $3^{\prime}$ and $5^{\prime}$-CGCCTGGAAGTTACTTTCTA-3'. Aliquots of the amplified DNA were mixed with one volume formamide dye buffer, denatured at $95^{\circ} \mathrm{C}$ for five minutes, and placed on ice; $4 \mu \mathrm{l}$ samples were loaded on a $5 \%$ non-denaturing polyacrylamide gel containing $10 \%$ glycerol and on a similar gel without glycerol. Electrophoresis was for three to six hours at $35 \mathrm{~W}$ and $5^{\circ} \mathrm{C}$. The gels were dried and exposed overnight to Kodak X-omat S film in order to visualise the separate bands.

\section{DIRECT SEQUENCING OF NORMAL MUTANT ALLELES}

To determine the nature of the shifted bands in the SSC analysis, $4 \mu \mathrm{l}$ of amplification product was loaded on a $6.6 \%$ denaturing polyacrylamide gel. The gel was electrophoresed at $60 \mathrm{~W}$ for three hours at room temperature, dried, and exposed overnight to Kodak X-omat $S$ film to visualise the bands. Bands representing wild type and mutant alleles were cut out of the gel. DNA was eluted from each of the gel slices in $50 \mu$ distilled water for one hour at $37^{\circ} \mathrm{C}$ and reamplified under the conditions described above. Subsequently, the amplified DNA fragments were purified by electrophoresis on a $1 \%$ agarose gel (one hour, $10 \mathrm{~V} /$ $\mathrm{cm}$ ), allowed to migrate into ultra low gelling temperature agarose (Sigma), and sliced out of the gel. This material served as substrate for direct sequencing using the Cycle Sequence $\mathrm{Kit}$ (BRL) according to the protocol of the manufacturer. Sequences were determined in two directions with the forward and reverse amplification primers after $5^{\prime}$ end labelling with ${ }^{32} \mathrm{P}$.

\section{Results}

A PAX3 GENE MUTATION IN A PATIENT WITH SPINA BIFIDA

PAX3 belongs to a family of embryonic transcription factors, which are related by pos- session of the conserved paired domain. The paired domain of the PAX3 gene is encoded by (part of) exons 2,3 , and $4 .^{26}$ In addition the PAX 3 gene contains two other conserved domains: an octapeptide motif encoded by a segment of exon $4,{ }^{26}$ and a homeodomain encoded by the $3^{\prime}$ and $5^{\prime}$ part of exons 5 and 6 , respectively. ${ }^{15}$ To test the hypothesis that mutations in the PAX3 gene might predispose to the development of NTD, genomic DNA was isolated from 39 patients of multiple case NTD families and the exons were screened for mutations by SSC analysis (Materials and methods, fig 1). When exon 5 was analysed, not only the normal band pattern, but several additional bands were observed in the DNA of one patient (fig 2A). To evaluate this further, the amplification products were subjected to denaturing gel electrophoresis, which showed the presence of a heterozygous deletion (fig 2B). The location and size of the deletion were determined by direct sequencing of the eluted allelic DNA fragments (Materials and methods). A 5 bp deletion was detected in exon 5 approximately $55 \mathrm{bp}$ upstream of the homeodomain (fig 3A). This causes a shift in the normal reading frame for translation with premature termination of polypeptide synthesis almost immediately downstream of the mutated site (fig 3B).

\section{CLINICAL EXAMINATION OF THE PATIENT AND} HER RELATIVES

Knowing that PAX 3 mutations can cause $\mathrm{WS}^{27}$ (MIM 193500), signs of this disorder could be present in the patient and some of her relatives. Therefore, the family (fig 4) was clinically (re)examined. The major signs of WS are a typical facies with dystopia canthorum as the most frequently observed characteristic, pigmentary disturbances like a frontal blaze of white hair, heterochromia irides, white eyelashes and leucoderma, and partial or complete cochlear deafness. WS follows an autosomal dominant pattern of inheritance with a wide variability of expressivity. ${ }^{20}$

The index patient (III.5) was seen at the age of $11 \frac{1}{2}$ years. She was born with a lumbosacral meningomyelocele for which she was operated on shortly after birth. Because of developing hydrocephalus, a ventriculoperitoneal shunt was inserted. She is mentally retarded. Her height is $128.5 \mathrm{~cm}$ ( $<3 \mathrm{rd}$ centile), she weighs $26 \mathrm{~kg}$ (50th centile for height), and has an occipitofrontal circumference of $53.7 \mathrm{~cm}$ (50th-90th centile). She has dystopia canthorum (ICD $43 \mathrm{~mm}$, >97th centile; OCD $85 \mathrm{~mm}$, 50th centile), leading to blepharophimosis, broad and high nasal root, hy- 

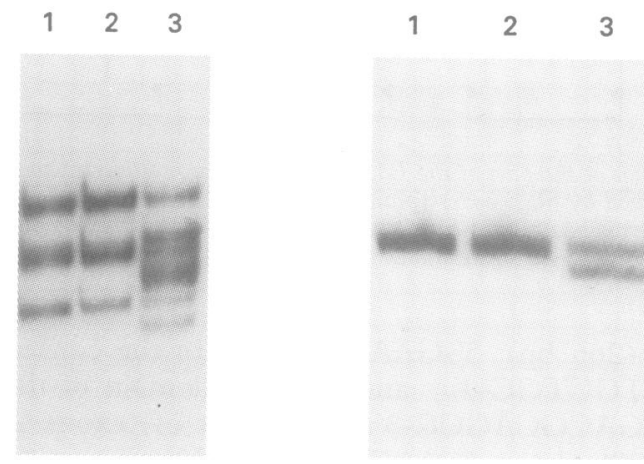

Figure 2 Molecular analysis of exon 5 of the PAX3 gene. Autoradiographs show the allelic band patterns obtained with (A) SSC analysis and (B) denaturing gel analysis of genomic DNA from two control persons (lanes 1 and 2) and from a patient with spina bifida (lane 3). With DNA from the patient, SSC analysis shows bands with abnormal mobility in addition to the wild type bands, indicating the presence of a heterozygous mutation in exon 5. On denaturing gel electrophoresis the aberrant allele appears to be of reduced length owing to a deletion.

poplastic nasal alae, a round nasal tip, and smooth philtrum. There is a naevus above the right eye. The palate is high arched and there is dental crowding. Below the spina bifida she has a deep sacral pit. She has no heterochromia irides, no pigmentary disturbances, and no hearing loss.

The mother of the index patient (II.4) has a similar appearance with dystopia canthorum (ICD $41 \mathrm{~mm}$, >97th centile; OCD $85 \mathrm{~mm}$, 25th-50th centile), leading to blepharophimosis, brushy eyebrows, a high nasal root,
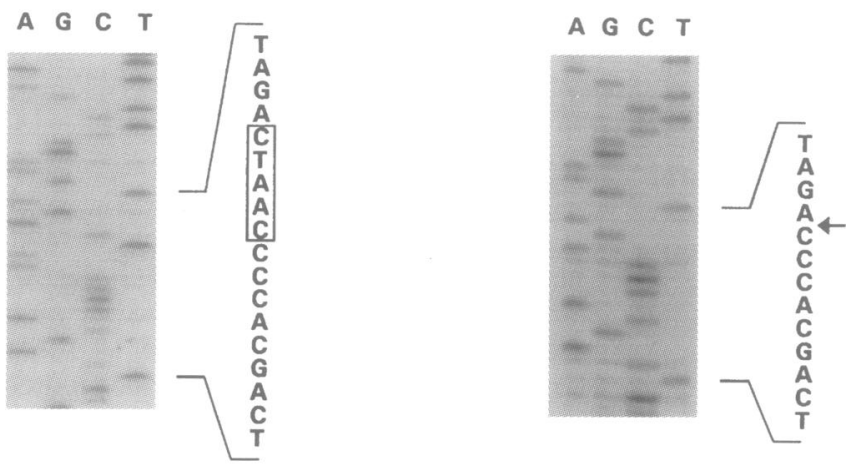

B

\section{Exon 4 \\ AGC GAG CGA GCC TCA GCA CCC CAA TCA GAT GAA GGC TCT GAT Ser Glu Arg Ala Ser Ala Pro GIn Ser Asp Glu Gly Ser Asp} Exon 5

\section{AGC GAG CGA GCC TCA GCA CCC $\times \times \times \times \times A G A$ TGA AGG CTC TGA $M$ Ser Glu Arg Ala Ser Ala Pro Arg $* \star \star$}

Figure 3 (A) DNA sequence of the normal $(N)$ and mutant $(M)$ allele of exon 5 of a patient with spina bifida as shown by cycle sequencing. The boxed sequence in the normal allele is deleted in the mutant allele. The arrow marks the site of the deletion in the mutant allele. (B) Partial cDNA and protein sequence of the region containing the deletion as deduced from the cycle sequencing results. The mutant gene contains a premature stop codon shortly after the site of the deletion. The boundary between exons 4 and 5 is indicated by a vertical bar. hypoplastic nasal alae, and a round nasal tip. She has vitiligo of the left hand and wrist. She has no heterochromia irides and no hearing loss.

The maternal grandfather of the index patient (I.2) has heterochromia irides and dystopia canthorum, but no pigmentary abnormalities and no long standing hearing loss. No abnormalities were seen on a photograph of the maternal grandmother (I.1).

The maternal aunt of the index patient (II.1) has no signs of WS. Another sister of the mother (II.3) was born with a lumbar meningomyelocele and hydrocephalus, but died at the age of 6 months without having left the hospital. It is unknown whether she had any sign of WS. No material was saved for genetic analysis.

Several sibs of the index patient III.4, III.8, III.9, and III.10, show the facial characteristics of WS. III.9 was born with a white forelock, which subsequently disappeared, and has unilateral hearing loss. III.8 had poliosis.

These observations show that WS is indeed segregating in this family and that the index patient has a mild expression of this syndrome in combination with spina bifida. Based on the presence/absence of specific symptoms, three subtypes of Waardenburg syndrome are distinguished. WS-I (MIM 193500) and WS-II (MIM 193510) are characterised by the presence or absence of dystopia canthorum, respectively, whereas the disorder is diagnosed as WS-III (MIM 148820) if limb deformities are among the symptoms. Accordingly, the present family can be categorised as having WS-I. So far, WS with NTD patients have only been reported in families with WS type I.

\section{CORRELATION BETWEEN MUTATION AND PHENOTYPE}

The pattern of inheritance of WS is compatible with that of an autosomal dominant disorder. To investigate further the relationship between the clinical signs and the mutation discovered in the index patient, exon 5 was amplified from the DNA of all available persons and analysed by denaturing gel electrophoresis. As can be seen in fig 5 , there is an exact correlation between the presence/absence of the abnormal allele and the phenotype $(\mathrm{Z}=+2 \cdot 40$ at $\theta=$ $0 \cdot 0$ ).

\section{Discussion}

The association between NTD and WS is well documented. Interestingly, of the 11 patients with NTD and WS reported since 1988, eight represent familial cases of NTD. ${ }^{19-24}$ This includes the index patient of the present study, who had a maternal aunt with spina bifida. Apparently, there is an increased recurrence risk of NTD in families with WS, which corroborates the common aetiology of both disorders. The molecular defect in two other patients with WS and NTD has previously been reported. ${ }^{12}{ }^{15}$ Both cases concern missense mutations in exon 2 changing an amino acid within the paired domain of the PAX 3 protein. 
I

II

III

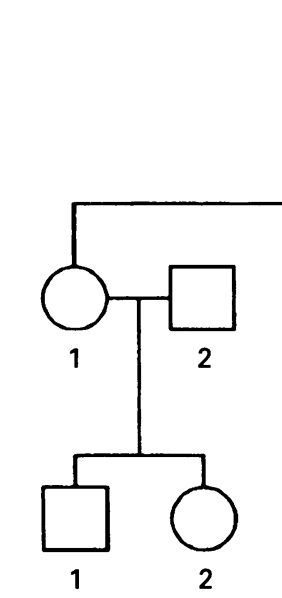

3

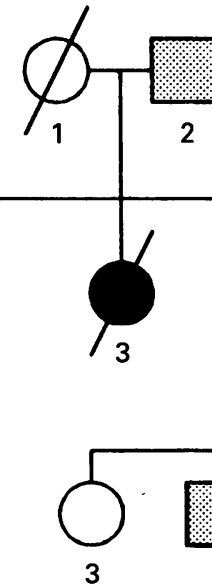

2

Figure 4 Pedigree of the family with two closely related patients with lumbar meningomyelocele and hydrocephalus: the index patient III.5 and her maternal aunt II.3. All members were clinically examined for symptoms of WS. Those with a positive diagnosis of WS in addition to the index patient are indicated by shaded symbols.

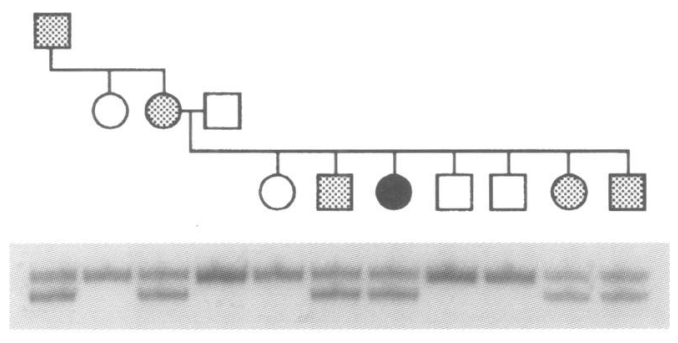

$\begin{array}{lllllllllll}\text { I.2 } & \text { II. } & \text { II. } & \text { II.5 } & \text { III.3 III.4 } & \text { III.5 III. } 6 & \text { III. } & \text { III. } & \text { III.9 }\end{array}$

Figure 5 Cosegregation of the exon 5 deletion with symptoms of WS. All available members of the family were analysed for the presence of the mutant allele by PCR amplification of exon 5 and subsequent denaturing gel separation of amplified fragments. All members diagnosed as having WS symptoms appear to carry the mutant allele.

Here we show that mutations disrupting the open reading frame of the PAX3 gene may also be found in patients with WS and NTD.

Despite the fact that carriers of a PAX3 mutation probably have an increased risk for NTD, in the present study only one of 39 patients with familial NTD was found to have such a mutation indicating that, in general, PAX 3 mutations are an infrequent cause of familial NTD. However, SSC analysis is not completely sensitive, leaving the possibility that some mutations have not been detected by this method. Further, mutations could be present in exons 1,7 , or 8 , which have not yet been examined in detail. Nevertheless, mutations within or near the conserved domains of the PAX3 protein are not likely to play a major role in familial NTD.

Because of the findings in Splotch mice, it is not surprising that NTD may be present in humans carrying a mutation in the PAX 3 gene. Homozygous Splotch embryos die on day 13 of gestation and $50 \%$ have lumbosacral spina bifida. Heterozygous animals display pigmentary disturbances, but have a normally closed neural tube, yet breeding experiments have shown that a heterozygous $\operatorname{Pax} 3$ mutation influences the incidence of NTD in animals already committed to NTD development. ${ }^{9} 10$ Apparently, in those animals the occurrence of NTD depends on a combination of pre- determining factors. A similar situation may exist in humans, where additional factors may modify the phenotypic expression of the same PAX3 mutation in different persons. Spina bifida is not the only malformation of homozygous Splotch embryos. In $50 \%$ exencephaly is observed and congenital heart defects also occur, which are regarded as the major cause of death. In humans, anencephaly and congenital heart defects do not seem to be associated with WS but, considering the influence of other genetic factors on the phenotype, it may be worth looking for PAX 3 mutations in patients with NTD and congenital heart defects.

The pathophysiological processes leading to NTD in Splotch have not yet been elucidated. Suggested mechanisms include delayed migration of neural crest cells and an abnormal curvature of the caudal region. More likely, these phenomena are secondary to a defect of the neuroepithelium, where the $\operatorname{Pax} 3$ gene is expressed before neural tube closure. ${ }^{10}$ The detection and functional characterisation of PAX3 gene mutations in patients with NTD may help to clarify the pathogenesis of NTD further.

We thank the working group "Hydrocephalus en Spina Bifida" of the Dutch patient organisation BOSK for their assistance in contacting families with NTD. We also thank Professor Dr H H Ropers for critically reading the manuscript, H Egtberts fo blood sampling, and $S$ van der Velde-Visser and $E$ Boendervan Rossum for cell culturing and EBV transformation. This study was financially supported by the Dutch Prinses Beatrix Fonds, grants no 90-3154 and 93-005. RAM acknowledge the support of Dr Harold Riethman, in whose laboratory his experiments were carried out (NIH grant CA47983).

1 Copp AJ, Brook FA, Estibeiro P, Shum ASW, Cockroft DL. The embryonic development of mammalian neural tube The embryonic development of mammalian

2 Chatkupt S, Lucek PR, Koenigsberger R, Johnson WG Parental sex effect in spina bifida: a role for genomic imprinting? Am f Med Genet 1992;44:508-12.

3 Mariman ECM, Hamel BCJ. Sex ratios of affected and transmitting members of multiple case families with neural tube defects. F Med Genet 1992;29:695-8.

4 Hol FA, Geurds MPA, Jensson O, et al. Exclusion mapping of the gene for $\mathrm{X}$-linked neural tube defects in an Icelandic family. Hum Genet 1994;93:452-6.

5 Lyon MF, Searle AG. Genetic variants and strains of the laboratory mouse. 2nd ed. New York: Oxford University Press, 1990.

6 Epstein DJ, Vekemans $M$, Gros P. Splotch $\left(\mathrm{Sp}^{2 \mathrm{H}}\right)$, a mutation affecting development of the mouse neural tube, shows a deletion within the paired homeodomain of Pax-3. Cell 1991;67:767-74

7 Goulding MD, Chalepakis G, Deutch U, Erselius JR, Gruss 
P. Pax-3, a novel murine DNA binding protein expressed during early neurogenesis. EMBO f 1991;10:1135-47.

8 Moase CE, Trasler DG. Splotch locus mouse mutants: models for neural tube defects and Waardenburg syndrome type I in humans. $\mathcal{F}$ Med Genet 1992;29:145-51.

9 Konyukhov BV, Mironova V. Interaction of the mutant genes splotch and fidget in mice. Soviet Genet 1979;15: gen-11.

10 Estibeiro JP, Brook FA, Copp AJ. Interaction between splotch (Sp) and curly tail (ct) mouse mutants in the splotch (Sp) and curly tail (ct) mouse mutants in the
embryonic development of neural tube defects. Deembryonic development of
velopment 1993;119:113-21.

11 Tassabehji M, Read AP, Newton VE, et al. Waardenburg's syndrome patients have mutations in the human homologue of the Pax-3 paired boxed gene. Nature 1992;355: $635-6$.

12 Baldwin CT, Hoth CF, Amos JA, da-Silva EO, Milunsky A. An exonic mutation in the HuP2 paired domain gene 3 causes Waardenburg's syndrome. Nature 1992;355:637-8. Morell R, Friedman TB, Asher JH Jr. A plus-one frameshift
mutation in PAX3 alters the entire deduced amino acid mutation in PAX3 alters the entire deduced amino acid sequence of the paired box in a Waardenburg syndrome

14 Tassabehii M, Read AP, Newton VE, et al. Mutations in the PAX 3 gene causing Waardenburg syndrome type 1 and type 2. Nature Genet 1993;3:26-30.

15 Hoth CF, Milunski A, Lipsky N, Sheffer R, Clarren SK, Baldwin CT. Mutations in the paired domain of the human PAX 3 gene cause Klein-Waardenburg syndrome (WS-III) as well as Waardenburg syndrome type I (WS-I). $A m \mathcal{F}$ Hum Genet 1993;52:455-62.

16 Morell R, Friedman TB, Moeljopawiro S, Hartono, Soewito, Asher JH Jr. A frameshift mutation in the HuP2 paired domain of the probable human homolog of murine paired is responsible for Waardenburg syndrome type 1 in
Pax 3 is ren of an Indonesian family. Hum Molec Genet 1992;4:243-7.

7 Butt J, Greenberg J, Winship I, Beighton P, Ramesar R. A splice junction mutation in PAX 3 causes Waardenburg syndrome in a South African family. Hum Molec Genet 1994;3:197-8.

18 De Saxe M, Kromberg JGR, Jenkins T. Waardenburg syndrome in South Africa. Part I. An evaluation of the clinical drome in South Africa. Part 1. An evaluation of the clinical

19 Narod SA, Siegel-Bartelt J, Hoffman HJ. Cerebellar infarction in a patient with Waardenburg syndrome. $A m \mathcal{f}$ farction in a patient with War

20 Da-Silva EO. Waardenburg I syndrome: a clinical and genetic study of two large Brazilian kindreds, and literature review. Am f Med Genet 1991;40:65-74.

21 Carezani-Gavin M, Clarren SK, Steege T. Waardenburg syndrome associated with meningomyelocele. $A m \mathcal{F ~ M e d ~}$ Genet 1992;42:135-6.

22 Begleiter ML, Harris DJ. Waardenburg syndrome and meningocele. Am f Med Genet 1992;44:541.

23 Chatkupt S, Chatkupt S, Johnson WG. Waardenburg syndrome and myelomeningocele in a family. 7 Med Genet 1993;30:83-4.

24 Moline ML, Sandlin C. Waardenburg syndrome and meningomyelocele. Am f Med Genet 1993;47:126.

25 Miller SA, Dykes DD, Polesky HF. A simple salting out procedure for extracting DNA from human nucleated cells. Nucleic Acids Res 1988;16:1215.

26 Burri M, Tromvoukis Y, Bopp D, Frigerio G, Noll M. Conservation of the paired domain in metazoans and its structure in three isolated human genes. $E M B O F 1989$; 8:1183-90.

27 Chalepakis G, Stoykova A, Wiinholds J, Tremblay P, Gruss P. Pax: gene regulators in the developing nervous system. f Neurobiol 1993;24:1367-84. 